\title{
A Natural History of You
}

\author{
Marcus Kumala
}

Published online: 13 October 2010

(C) Springer Science+Business Media, LLC 2010
April 1 2007; Sample I Janurary 24 2006). Animal lovers rejoiced, moralists stammered and ridiculed, while most scientists were oblivious to the one thing they all shared in common: they were all stuck with Linnaeus back in 1758 .

Many are undoubtedly familiar with the use of Latin binomials (i.e., Panthera tigris) arranged into progressively higher orders of rank (i.e., species $\rightarrow$ genus $\rightarrow$ order $\rightarrow$ class $\rightarrow$ kingdom) in traditional scientific classification; it's what we were taught in grade school and what we continue to teach. Unfortunately, we're about 50 years or so behind the actual science (and those within the scientific community are far from exempt). Unbeknownst to most, when Swedish botanist Carolus Linnaeus devised the system that would become his namesake, it was more than just taxonomic housekeeping. Linnaeus fancied himself to be a "second Adam," ordained by God to assign every plant, animal, and mineral its proper place in the natural order. In his own words, "God created, Linnaeus arranged." It was during the tenth edition of his hailed Systema Naturae (1758) that Linnaeus blessed humanity with the species name sapiens and placed us in the genus Homo at the head of a revised table, the order Primates, meaning of "first rank" (Douthwaite 1995; O'Flaherty and Shapiro 2002). But we were not alone.

Undoubtedly influenced by the discovery and tales of anthropomorphic apes or orang outangs Moran 1993, Linnaeus divided the genus Homo into Men of Darkness (Homo nocturnus) or Troglodytes ("cave-dwelling men") and Men of Light (Homo diurnus), which included Adamite men (Homo sapiens), monstrous men (Homo monstrous), and wild or "feral" men (Homo ferus; Douthwaite 1995, 1997). Over time, both legend and actual specimens intertwined, and when the dust settled, the common chimpanzee, or Troglodyte, was kicked out of the genus Homo and placed in the genus Pan (Oken 1816). Now to the casual observer, this might seem rather trivial, but the move signified more than just a taxonomic reshuffling; it 
removed the beast from the hallowed chambers of man and fully projected the element of the demonic upon the innocent ape through the intersection of humanity, darkness, and unbridled sexuality (the horns, hooves, and phallus of the Greek satyrs and god Pan meets the Christian Satan). The bonobo, Pan paniscus (Schwarz 1929), far more deserving of the fun-loving satyr imagery, would soon join its cousin, Pan troglodytes, in purgatory (Fig. 1).

As it is difficult to show the blood relationship between the numerous kindred of any ancient and noble family even by the aid of genealogical trees, and almost impossible to do so without this aid, we can understand the extraordinary difficulty which naturalists have experienced in describing, without the aid of a diagram, the various affinities which they perceive between the living and extinct members of the same great natural class. (Darwin 1872)

Appeals to authority and subjective notions of similarityfundamentally no different than the "yardstick" applied by geneticists spouting percent differences-formed the basis of taxonomic practice well into the twentieth century. Darwin's vision of a taxonomy that actually reflected a "community of descent," or genealogy, would have to wait until German entomologist Willi Hennig laid out the groundwork for what we now call Phylogenetic Systematics, or Cladistics. In a nutshell, phylogenetics is the scientific discipline of classifying organisms based on evidence of similarity due to common ancestry (homology). More precisely, this comes in the form of shared, special homologies or synapomorphies. For example, among Amphibia, Mammalia, and Reptilia (including birds), Mammalia and Reptilia are considered more closely related because they share a number of synapomorphies thought to have originated in their common ancestor, such as the amniotic egg.

Brevity prevents me from going into more detail (see reference Brooks and McLennan 2002 for a detailed description of the phylogenetic method), but the purpose of phylogenetics is the discovery of monophyletic groups, which are natural assemblages that contain an ancestral species and all of its descendants. The members within a monophyletic group share a unique set of relationships compared to species placed outside the group (Wiley et al. 1991). Only species (unique lineages or branches) and monophyletic groups are considered to be natural taxa because they exist in nature as a result of evolution, or "descent with modification." In this sense, Linnaean ranks are obsolete because the same organisms would exist in a group whether you called it a class, an order, or a family. Below is an example of a phylogeny with several monophyletic groups identified by a simplified set of easily recognizable synapomorphies (Fig. 2).

Why is this relevant to you as secondary school teachers? The feeling of disconnect described during the outset is something quite palpable in our approach to teaching the biological sciences. Too often we portray the human body as some kind of independent wonder instead of paying homage to it as a wondrous product of natural history. We describe and often teach the strands of biology as disjointed units when we have a real opportunity to portray it as a cohesive discipline by building around an evolutionary framework. This will prove to be even more important as the Internet Age continues to provide us with access to an incredible amount of information while pushing us to the very limits of filtration for meaning. Biology, and science in general, will need clear, robust
Fig. 1 A phylogeny of the "Great Apes"
"The Great Apes"

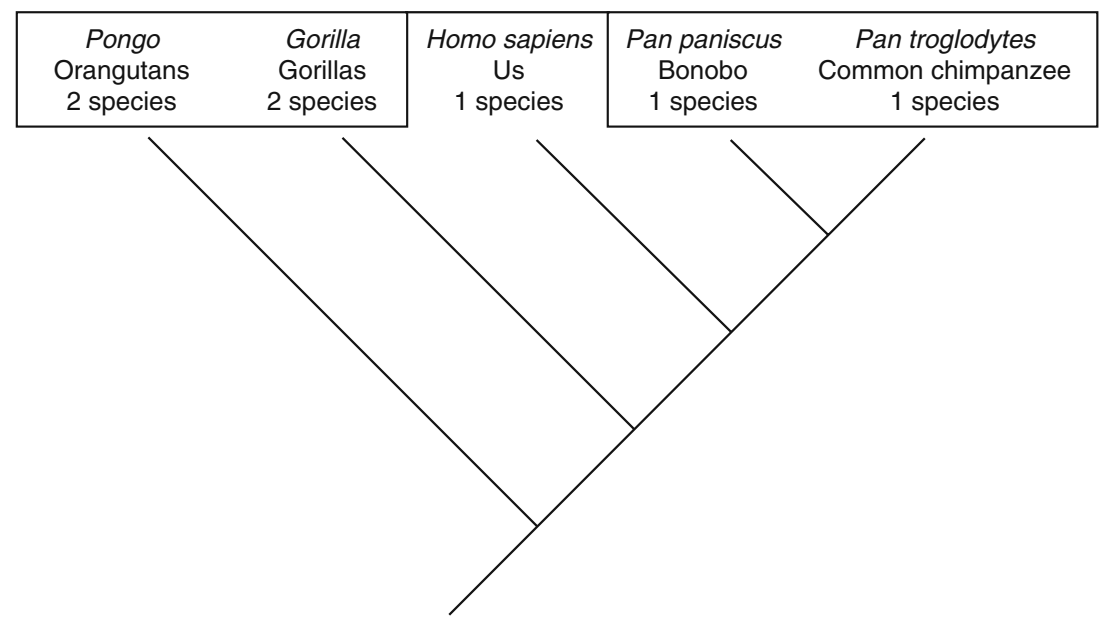




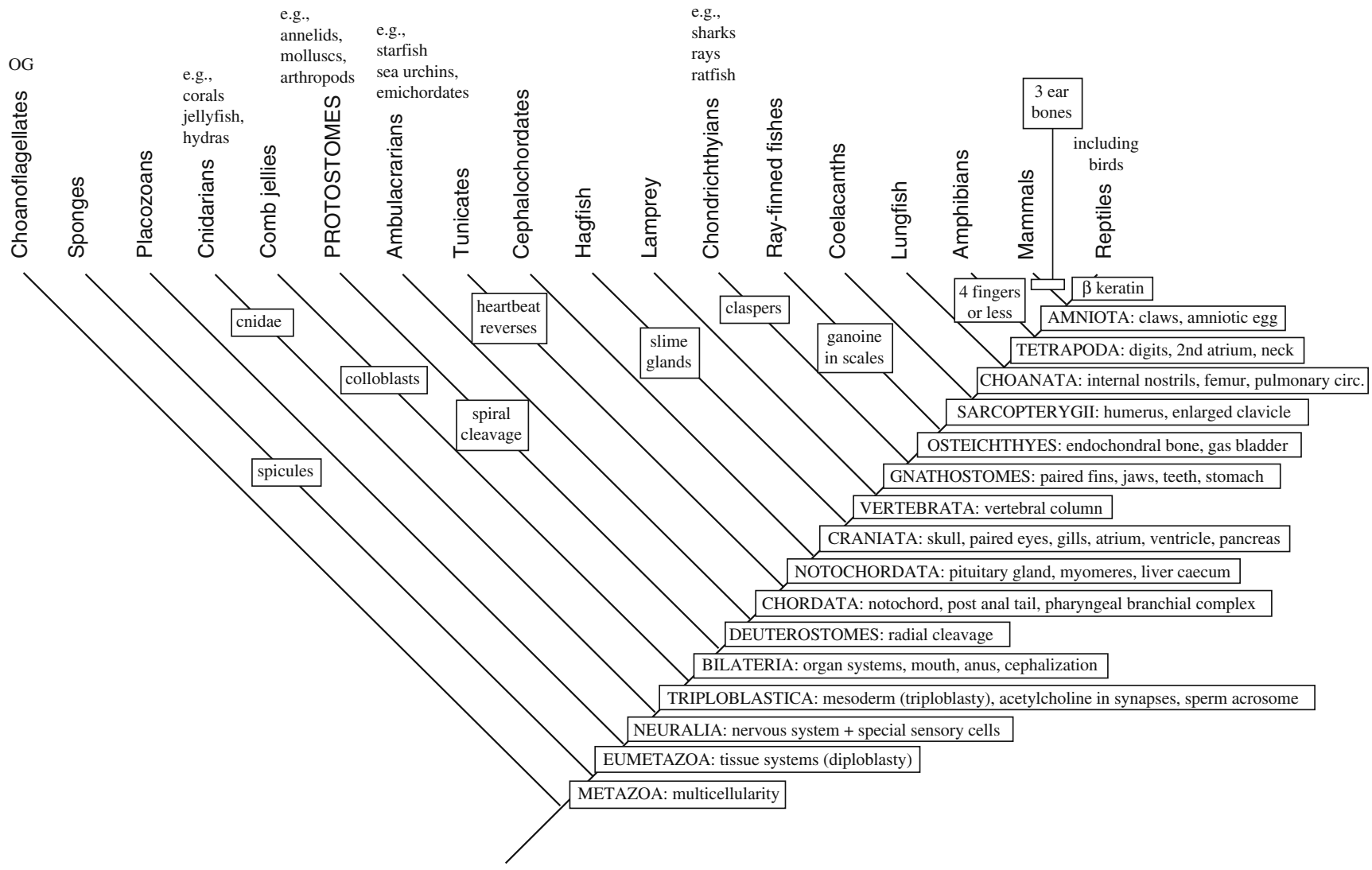

Fig. 2 A phylogeny of animals (Metazoa)

foundations from whence new information can flow and return, and there is no reason why biology cannot be taught as a unified macroevolution course, particularly at the senior level.

Beyond the level of species, much of the name game is indeed semantic. Whether there is greater value in keeping Pan to specifically identify the monophyletic group of common chimpanzees and bonobos rather than absorbing it within Homo really depends on whether you're a "lumper"- prefer to name just a few monophyletic groups with lots of species in each - or a "splitter"prefer to name a lot of groups to emphasize diverse relationships. But never forget that you are more than just Homo sapiens: You are also a Craniate, a Vertebrate, a Gnathostome, a Bony Fish, a Lobe-finned Fish, a Tetrapod, an Amniote, a Mammal, a Placental Mammal, a Primate, an Old World Monkey, and even a Great Ape, which would be an unnatural grouping without our inclusion, just to name a few. We have a lifetime membership in a shared history that stretches all the way back to the first cell. And just for clarification, since evolution is "descent with modification," you are not a hagfish (Myxiniformes) or a ray-finned fish (Actinopterygii) unless you happen to sport slime glands and ganoine scales, respectively. I'm sure that'll both spark curiosity and offend in more ways than the selfconscious ape in the mirror. "A rose by any other name would smell as sweet..."

Bart: Not if you called 'em stenchblossoms

Homer: Or crapweeds.

Marge: I'd sure hate to get a dozen crapweeds for

Valentine's Day. I'd rather have candy.

Homer: Not if they were called scumdrops ("The

Principal and the Pauper," The Simpsons 1997)

\section{Appendix}

A Natural History of You Activity: Note to Teachers

It's one thing to discuss the wonderful nuances of evolutionary theory in theory, but it's another thing to 
actually observe, handle, and explore the physical products of "descent with modification." The following activity was designed to reinforce principles in contemporary evolutionary thought through student inquiry, as well as to provide a potential framework for exploring all strands within the biology curricula from cells and systems to the diversity of life, to even specific units like respiration. While there are many possible ways to conduct this activity, the preferred method would involve creating activity stations with combinations of preserved/live specimens, information sheets, and photographs/video. Although the likelihood of either owning or having access to such a diversity of organisms is low, one can build up quite a useful collection in a short span of time and rely more heavily on diagrams, photographs, and videos in the interim (which are readily available on the Internet).

The first activity involves reinforcing the basics of the phylogenetic method. Students are expected to have been instructed on how to read a phylogeny and should be familiar with basic terminology before conducting such a lab. As they go from station to station, they are expected to fill in the missing synapomorphies on the phylogeny provided (Fig. 3). These can be described on information sheets created ahead of time. The completed phylogeny can now serve as their historical "map" to be used in the next activity, which is a diagram highlighting several features of the human body. Using their completed phylogeny (Fig. 1), students can trace the origins of these homologous traits and subsequently identify their membership in several nested groups (Fig. 4). For example, the presence of endochondral bone and toes makes us members of the Osteichthyes (or "Bony Fish") and Tetrapoda respectively. At the same time, since it is "descent with modification," students will have an opportunity to discover how they are different from other organisms and yet still related (i.e. male humans don't have reproductive organs called "claspers" and hence are not members of a group containing sharks and rays, but we are still Gnathostomes). The final activity provides an opportunity for students to visualize how extinction produces a loss of biological information, and how each new fossil offers us an opportunity to add a few more pieces to the genealogical puzzle.

In theory, this diverse approach will engage a wide spectrum of learning styles in the hope that at least one of these activities will create a sense of wonderment and appreciation for the history of life on our planet. Ideally, this would be the beginning of a cohesive approach to the biology curriculum where each strand could now naturally flow out of particular branches of the tree of life. However, I acknowledge the challenges that change presents, and offer that this could be used quite effectively in a far more limited capacity as well. Potential follow-up lessons/ activities could include a similar lab using genetic data or case studies exploring how the predictive power of phylogeny can provide valuable insight into medicine and the control of pathogens.

Additional Resources:

Kardong, K.V. 2002. Vertebrates: Comparative Anatomy, Function, Evolution. Third Edition, The McGraw-Hill Companies, Inc: New York, NY:

PALAEOS: The Trace of Life on Earth. http://www. palaeos.com/Default.htm

Tree of Life Web Project. http://tolweb.org/tree/

\section{A Natural History of You Worksheet}

Removed from the context of natural history, it is easy to think of the human body as an independent marvel. But the human body is in fact the product of a marvellous history of "descent with modification." As a result of common ancestry, you are "specially" similar in some but not all ways to other living things, and by extension, you are more related to some organisms than others. We call these shared, similarities synapomorphies (say it with me "suh-nah-po-morphy"), a particular or "special" type of homology.

Who am I? What am I? What am I not? By examining the origins of several features of the human body, we may find answers to some of these questions. So get ready to go on a journey through time! The answers may surprise you young Bony Fish...

Your task:

In pairs, make your way through the Animal or Metazoan branches of the Tree of Life, our "Ingroup" of study for today (you can start at any of the stations).

Your official tasks will be as follows:

1. Proceed from station to station and start to fill in the missing character traits on the phylogeny provided. The missing characters can be found once you examine the information sheets available. This phylogeny will essentially function as your "map."

2. After completing your "map" (or while you're completing it if you prefer), examine the attached diagram of the human body. Your task is to identify some of the major clubs, or rather "clades," you belong to as a 
result of common ancestry.

First, locate the origin of the highlighted feature(s) on your phylogeny, and whenever you see the letter "A," write down the name of the inclusive group you ALL belong to as a result of sharing this trait. Second, although you are not a member of this group, whenever you see the letter "B," identify the oldest surviving members that also share this trait, an exclusive group you don't belong to.

3. Your final task is to apply your growing knowledge of phylogenetic systematics or "cladistics," by hypothe- sizing where the following extinct species belong on your phylogeny: Pikaia, Dunkleosteus (a "placoderm"), Haikouichthys, Cephalaspis (an osteostraci), Eusthenopteron, and Tiktaalik. Read the information sheets and diagrams at the final station, and place the extinct lineages on your phylogeny with a dotted line that ends prematurely.

Your informal tasks: Explore the stations set up, search for structures, ask questions, and enjoy! (;)

Feedback/Comments/Notes:

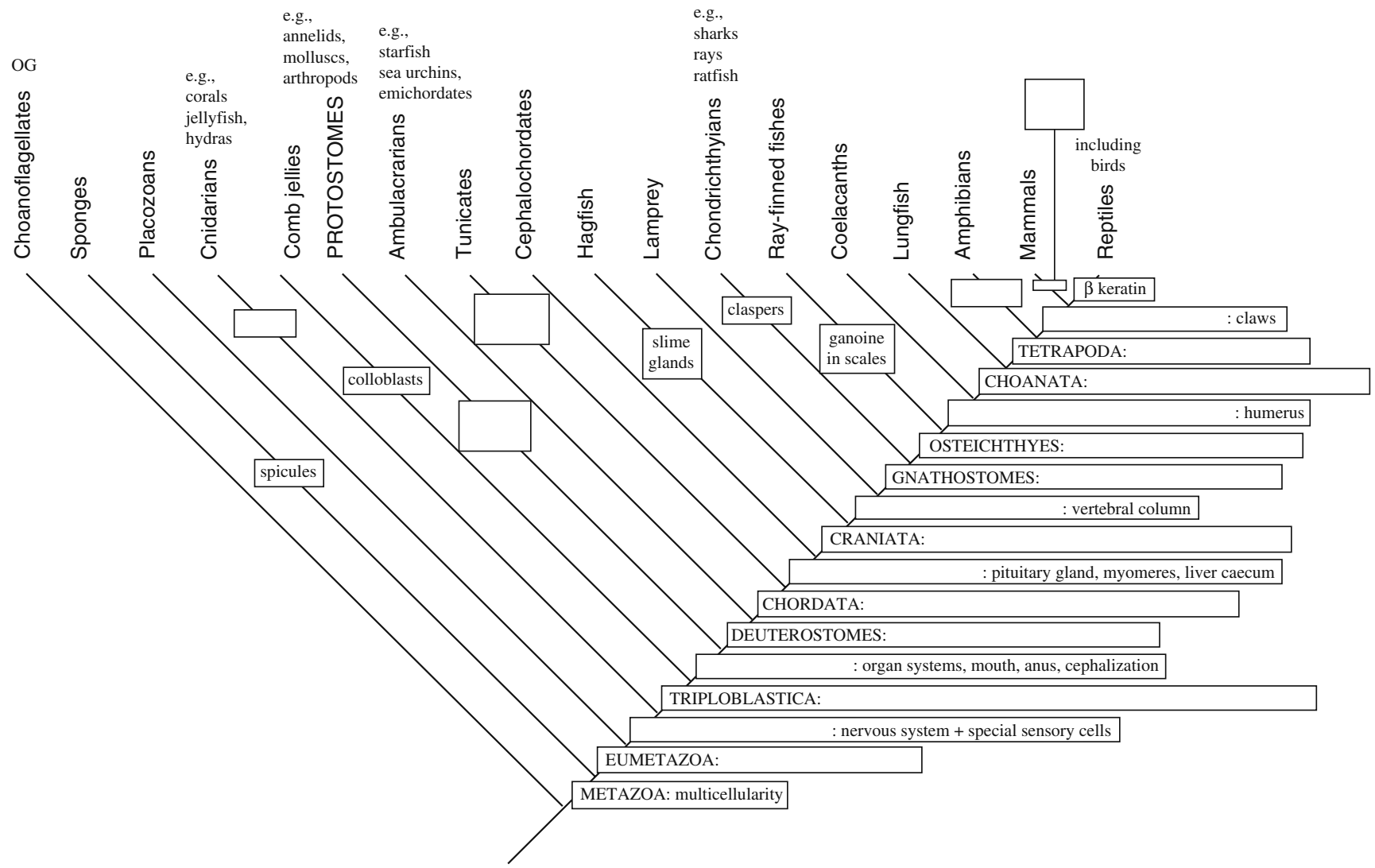

Fig. 3 Animal phylogeny worksheet 


\section{A Natural}

History of You

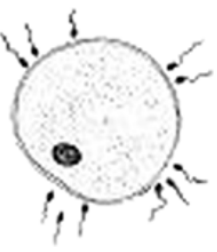

sperm with acrosome (B)

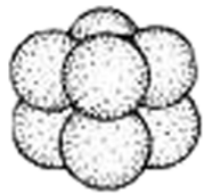

multicellularity

(A)
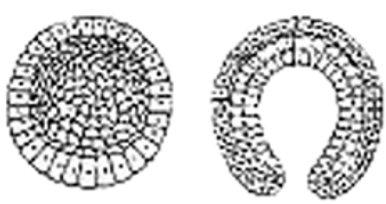

radial cleavage

(A)

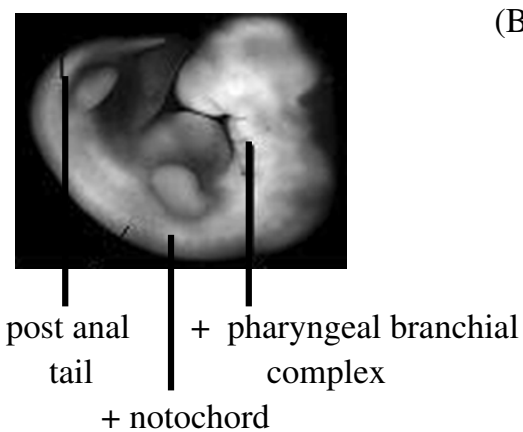

(A)

(B)
3 inner ear bones $(\mathrm{A})$

paired eyes (B)

vertebral column

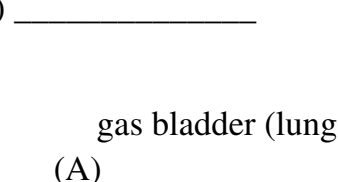

(B)

liver
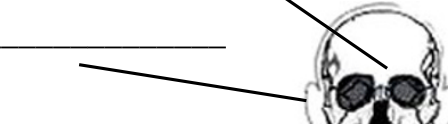

nervous system (B)

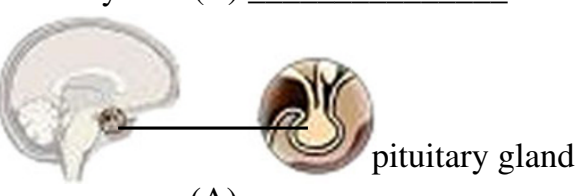

(A)

internal nostrils (A)

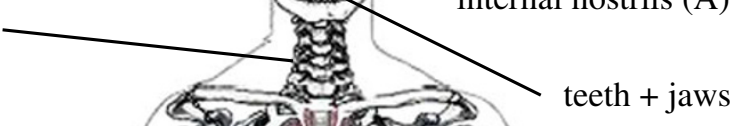

(A)

humerus (A)

atria + ventricle

(B)

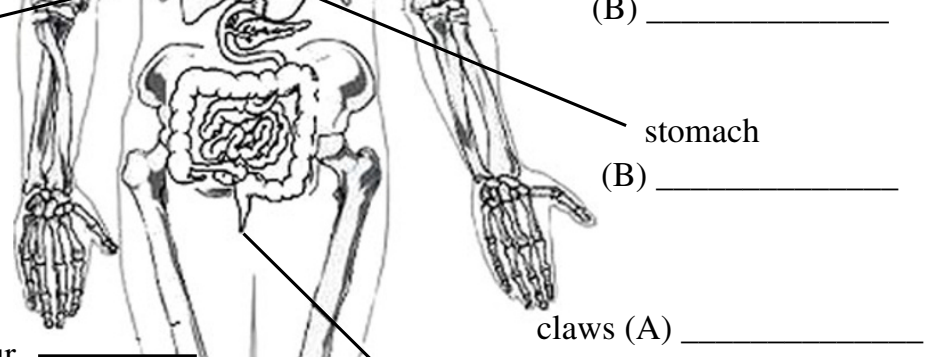

(B)

endochondral bone

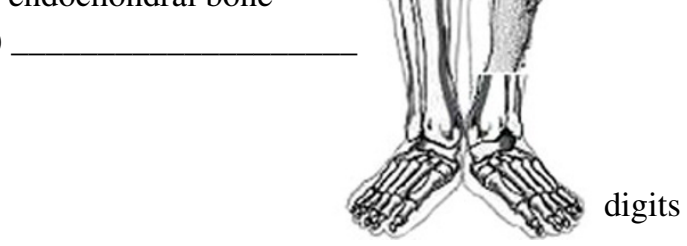

For example, consider the trait "digits" (such as toes):

The presence of this trait makes me (A) (a Tetrapod)

but I am not (B) (an Amphibian)

Fig. 4 Exploring the origin of the human body worksheet 


\section{References}

Brooks DR, McLennan DA. The nature of diversity: an evolutionary voyage of discovery. 1st ed. Chicago: The University of Chicago; 2002.

Connolly K (April 1, 2007) "Court to rule if chimp has human rights." The Observer

Douthwaite JV. Rewriting the savage: the extraordinary fictions of the "wild girl of champagne". Eighteenth-Century Stud. 1995;28:163-92.

Douthwaite JV. Homo ferus: between monster and model. EighteenthCentury Life. 1997;21:176-202.
Moran III F. Between primates and primitives: natural man as the missing link in Rousseau's second discourse. J Hist Ideas. 1993;54:37-58.

O'Flaherty B, Shapiro JS. Apes, essences, and races: what natural scientists believed about human variation. New York: Department of Economics, Columbia University; 2002. p. 1700-900. Discussion Paper \# 0102-24.

Sample I (Janurary 24, 2006) "Closer to man than ape". The Guardian Wiley EO, Siegel-Causey DJ, Brooks DR, Funk VA. The complete cladist: a prime of phylogenetic procedures. 1st ed. Lawrence: The University of Kansas, Museum of Natural History; 1991. 